\title{
Using Gambling Simulators to Foster Awareness About Gambling Risks: A Focus on Emotions
}

\author{
Chiara Andrà ${ }^{1} \cdot$ Nicola Parolini $^{1} \cdot$ Marco Verani $^{1}$
}

Published online: 16 September 2015

(C) Springer International Publishing 2015

\begin{abstract}
Stemming from an interest in developing suitable didactical tasks to prevent gambling abuse during the school years, this article explores the use of an Android app that simulates the outcomes of a well-known Italian instant lottery. Some features that characterize the phenomenon of gambling abuse are sketchily recalled, the Android app is presented and an example from a classroom task is discussed. We conclude that the simulator contributes to developing statistical literacy, as traditional random generators do, and also exploits emotional reactions, such as shock, which allow curiosity to emerge and pave the way towards deeper understanding.
\end{abstract}

Keywords Touchscreen app · Gambling abuse prevention · Emotions

\section{Introduction}

Betting games have traditionally constituted a stimulating context for the teacher to introduce basic concepts of probability into her classroom: Siller and Maaß (2012), for example, underline the fact that the topic of probability taught for understanding gambling "is a very authentic one, so that the students have the possibility to discuss a real-life problem which could be found in their near environment" (p. 65), and the context prompts the students to "use mathematics as a decision support" (p. 65, Siller and Maaß 2012). This article, without rejecting this tradition, focuses on a phenomenon that has dramatic social consequences: gambling abuse. This phenomenon is complex and involves psychological, social, relational and cognitive variables. A key feature is the gambler's inability to stop gambling: broadly speaking, after a win, since some money is earned, a gambler does not leave the game because she wants to earn even more money; after a loss, a gambler does not leave the game because she wants to recover the money she has lost

Chiara Andrà

chiara.andra@gmail.com

1 M.O.X. - Dipartimento di Matematica, Politecnico di Milano, Milan, Italy 
(see also Kahneman et al. 1982). Given the very low probability of winning significant prizes, and the unfairness of games, gamblers do not usually stop betting and lose more and more money.

Why do we care about school learning when dealing with gambling abuse? A general argument is that the persistent expansion of gambling has its roots in mathematical illiteracy. Contucci (2012) emphasizes that the expenditure in gambling decreases with the increase of scientific culture and concludes that mathematics education is a key factor in decreasing the risk of gambling abuse. Not only knowledge but also beliefs about gambling play a role: Bastiani et al. (2011) report a relationship between beliefs and behaviour, in that those students who disapprove of gambling also play less. Nonetheless, newspapers, TV programs, radio news and media in general contribute to develop misconceptions about gambling, inducing people to believe that gambling represents a genuine opportunity to "change one's life" (see also Capitanucci 2012). School plays a major role in developing and sustaining awareness about this dangerous view of life (Capitanucci 2012) and mathematical models can provide a better understanding of the experience of loss (see also Gigerenzer 1991).

The research project BetOnMath (http://betonmath.polimi.it) promotes student tasks that focus on gambling and originate from real gambling experiences. The learning trajectory can be conceived of as involving four phases (it follows a general structure proposed by Roth and Radford 2011): (i) the students simulate real gambling activities, using a touchscreen app that works as a random generator; (ii) the students share experiences of loss and engage in a sense-making process by drawing on their everyday concepts; (iii) a "mathematization" of the phenomenon begins, prompted by the teacher, firstly in small groups (the students discuss and propose a solution to the problem posed by the teacher, while the teacher in turn interacts with each group); (iv) a general discussion follows and outcomes from each group are collected, compared and generalized. In this article we investigate the role of the touchscreen app within the students' activity, hence focusing on phase (i).

\section{Theoretical Background}

Our research stems from Radford's (2008) cultural-semiotic approach that considers cognition as a reflexive mediated activity. Within this view, cognition is a shared practice involving the individual as a whole (both mind and body) and is accomplished in the socio-cultural contexts to which he or she belongs. Mathematical tasks are carried out through a set of resources (mediation), which directs the individual's intentional acts (reflexivity). Resources include: natural language (oral and written), gestures, objects, artefacts, bodily actions and mathematical symbolic language. To learn is to become a participant in a mathematical activity, one which is sensitive to context and allows the growth of mutual understanding and co-ordination between the individual and the rest of the community. Andrà and Santi (2013) further observe that this approach is specifically interested in how people think when they learn, rather than generally how they think, as, conversely, most cognitive psychologists do (e.g., Gigerenzer 1991; Kahneman et al. 1982). Emotions comprise a constitutive part of learning, since they determine the movement of consciousness and develop throughout the students' activity. Specific to gambling, we can notice that betting is an emotionally charged activity, one which 
involves the individual as a whole. Emotions, however, do not disappear when learning arises from experiences of gambling. Conversely, emotions go on with perception and cognition:

Like all other mental functions, emotions do not remain in the connection in which they are given initially by virtue of the biological organisation of the mind. In the process of social life, feelings develop and former connections disintegrate; emotions appear in new relations with other elements of mental life. (Vygotsky 1999, p. 244).

Drawing on the work of Vygosky, Radford (2014) suggests that, "there is no dividing line between thought, body, and emotion" (p. 33). In his view of sensuous cognition, Radford (2013) argues that our tactile-kinesthetic bodily experience of the world and our interaction with artifacts are much more than merely auxiliary to our cognitive endeavours. Sensuous cognition refers to a non-dualistic, non-representational, and noncomputational view of the mind. Starting from the premise that cognition and environment are inter-related entities, the basic idea is that cognition is a feature of living bodies characterized by a capacity for responsive sensation. Maintaining that emotion cannot be identified with perception, and that emotional reactions cannot be reduced to the biological disturbances such as sweat, tears or increased heart rate (Radford 2014), Roth and Radford (2011) see emotions as the engine that provides the motive for the activity to go on. In the learning process, emotions are not a trait-like feature of the subject, but rather they constitute a holistic expression of the subject's current state with respect to the object and the subject's sense of likelihood of success. Emotions can provide the learner with a sense of likelihood of success and enhance her actions, or they can provide her with a sense of likelihood of failure and thus impede her actions.

Perception is, according to the construct of sensuous cognition (Radford 2013), the substratum of mind and is culturally shaped. Perception is a sensing form of action and reflection, which can lead to cultural-historical forms of mathematical generalization. Touch and sight are, specifically for perception, the focus of this article. As regards touch, we draw on Sinclair and de Freitas' (2015) observation that there is significant conceptual traffic between gesture and touch. The nature of this traffic is related to the particular media in question. In our case, as we shall present later, the app activates touch, touch activates gestures (scratch, click) - and gestures activate touch. Sinclair and de Freitas (2015) empasize that traditional studies on gestures tend to divorce the motoric finger (gesture) from the feeling finger (touch). This article, indeed, agrees with Sinclair and de Freitas about the deep intertwined relationship between touch and gesture. As regards sight, Radford (2010) suggests to focus specifically on the way in which teachers create the possibility for students to perceive things in certain ways and encounter a cultural mode of generalizing. This new way of seeing in certain efficient cultural ways entails a transformation of the eye into a sophisticated theoretician. In fact, sight activates noticing. Noticing is, according to Mason (2011), a potentially intentional act. To notice requires attention to something, hence noticing requires both observation and the object under observation. Noticing relates to attention, consciousness and awareness. If learning is seen as a process through which students gradually become acquainted with historically constituted cultural meanings and forms of reasoning (Radford 2008), these processes entail a moment of poesis: a moment of 'bringing-forth' something to the realm of attention and understanding. 
Poesis is a creative moment of disclosure - the event of the thing in consciousness (Radford 2010).

Furthermore, such a moment of disclosure is both cognitive and affective - Radford's (2014) contention is that our thinking is necessarily embodied and emotional:

Only computers can "think" without feeling anything. They do not even feel the heat of their chips. They feel nothing. They display pure mechanical calculations of which humans are definitely incapable. We can make some calculations, and we can do it while feeling boredom, thrill, excitement, challenge or something else; what we cannot do is simply feeling nothing. (p. 33).

\section{The Research Design and the Simulator}

Gigerenzer investigated risk communication in situations where risks can actually be calculated or precisely estimated. He has developed an ecological approach (Gigerenzer and Selten 2001) to risk communication where the key point is the match between cognition and the presentation of the information in the environment. Disagreeing with previous studies in cognitive psychology (e.g., Kahneman et al. 1982), Gigerenzer (1991) has provided evidence that it is the representation of the information that counts, not only the human mind, and he has introduced the idea of natural frequencies, to address the natural human capability to understand simple graphs. Based on these considerations, we present the design of the simulator, but in the analysis of the excerpt we need to go beyond them, to take into account the shift from thinking to thinking in learning.

The simulator is a random generator that simulates the outcomes of an instant lottery that is well-known in Italy: the cost of the ticket for this instant lottery is 5 euros. The ticket is to be scratched in the following way: on the top row, 5 "winning numbers" are revealed, then on the bottom row 10 other numbers should be scratched, each of which is assigned a prize. If one out of the ten numbers in the bottom row equals one of the five winning numbers, the player wins the corresponding prize. Based on the issuing of 30,000,000 tickets, Table 1 reports the prizes and the number of corresponding winning tickets for each prize.

The probability of getting a prize with the simulator is the same as in the instant lottery, with most of the tickets getting no prize $(61.5 \%)$, many tickets winning small prizes, such as 5 euros $(28.7 \%)$ or 10 euros $(6.8 \%)$, and fewer and fewer tickets winning the higher prices, up to 500,000 euros $(0.0000167 \%)$. Two interesting mathematical tasks can be carried out: one that enhances the awareness of the very low probability of winning a prize higher than

Table 1 The number of winning tickets from the issuing of 30,000,000 tickets

\begin{tabular}{llll}
\hline Prize (in euro) & Number of tickets & Prize (in euro) & Number of tickets \\
\hline 500,000 & 5 & 50 & 120,000 \\
100,000 & 25 & 25 & 90,000 \\
10,000 & 250 & 20 & 270,000 \\
1000 & 5000 & 15 & 350,000 \\
500 & 7500 & 10 & $2,030,000$ \\
100 & 65,000 & 5 & $8,610,000$
\end{tabular}


the price of the ticket, and one that enhances an awareness about the unfairness of such games. In fact, the price of each ticket is 5 euros, but the average prize is about 3.50 euros. This article is concerned with the second kind of task. The simulator allows the students to simulate the outcomes of large numbers of scratches of the instant lottery and to visualise them on a graph reporting the money spent (i.e., a straight line with slope 5) and the money earned in term of prizes (i.e., a random curve "around" a straight line with slope 3.5). The students interact with the simulator before any mathematical content regarding gambling has been introduced.

Research in statistics education points out the emergence of a set of fundamental ideas for the teaching of statistics, such as: data, variation, distribution and representation (Burrill and Biehler 2011). Garfield and Ben-Zvi (2008) suggest developing these concepts in informal ways first and then shifting to more formal notions. According to them, exploring data and carrying out simple experiments, before subsequent formal studies in the context of the Central Limit Theorem, helps the students to develop an understanding of what concepts actually mean. In our wider perspective on learning as becoming a participant engaging in a mathematical activity, we see such experiments as comprising an unavoidable basis for learning to take place. We thus exploit Exploratory Data Analysis (EDA), introduced by Tukey (1972), whose working principle consists in looking at the data, valuing: i) graphical displays; ii) numerical summaries; iii) the natural pattern-recognition capabilities that people possess (in line with Gigerenzer 1991). Gal (2002) stresses that a key component of statistical literacy is the ability to interpret and evaluate statistical information, data-related arguments or stochastic phenomena critically, any of which may be encountered in diverse contexts. Specifically, Gal maintains that statistical literacy can contribute to people's ability to make choices when confronted with chance-based situations (e.g., buying lottery tickets or insurance policies, or comprehending medical advice).

We interpret EDA as firstly handling (many) simulations of a phenomenon, then looking for similarities among the different outcomes, and finally trying to find out a mathematical explanation for these similarities. Lane and Peres (2006) observe that simulations can play a significant role in enhancing students' ability to grasp statistical concepts. Lane and Tang (2000) compare simulations and textbooks with respect to their effectiveness for teaching statistical concepts. Eichler and Vogel (2014) observe that computer-based simulations support students in building a model, since the phenomenon is condensed in time and available for the students to work with. Thus, formal mathematics could be reduced to a minimum, allowing students to explore underlying concepts and to experiment with varying set-ups. Framing these considerations within a cultural-semiotic approach, we can say that the students are engaged in mathematical activity, one where the mediator is the simulator, where the actions are the gestures made in order to communicate with it (touch), and about it (speaking with the classmates), and where reflection is primarily about the outcomes of the simulator. Bartolini Bussi and Mariotti (2008) elaborate on the Vygotskian idea of semiotic mediation, aimed at describing and explaining the process that starts with the student's use of an artefact and leads to the student's appropriation of a particular mathematical content. They postulate that an artefact can be exploited by the teacher as a tool of semiotic mediation to develop genuine mathematical signs, detached from the use of the artefact, while still maintaining a deep semiotic link to it: this is the semiotic potential of the artefact. The evolution of signs, corresponding to the move from personal meanings rooted in the context of the artefact to conscious mathematical meanings, is a long-term process that is neither spontaneous nor to be taken for granted. The first move of the task 
with our app concerns the act of virtually scratching a ticket on the touchscreen, a blend of action (the moving finger) and perception (the sensing finger and the eye). Sight allows a student's sensibility to notice, to become aware of the many features of the app: as the students become conversant with it and its possible uses, they also become aware of the functioning of the real game, and their emotions frame their actions and reflections during their activity.

Our instant-lottery simulator has been implemented as an Android app (using the MIT app inventor platform http://ai2.appinventor.mit.edu). Availability and surprise are two reasons for developing a simulator suitable for smartphones: on the one hand, in fact, smartphones are, among all the technological devices, the one which is more commonly used by the students for communication and leisure activities (hence, on average, in each class there are at least 5-6 smartphones that can be used for group activities, one smartphone per group); on the other hand, the fact that the use of personal smartphones in classes is allowed provides an element of surprise for Italian students, one which can enhance creativity, thinking, intuitions (see also Liljedahl 2013). These "a priori" considerations found confirmation in our extensive classroom observations during April-June 2014: we monitored 23 secondary school classes that carried out activities based on the use of the instant-lottery simulator.

The app has a very simple structure and is extremely easy to use, so that it does not even require any introduction before students are able to start to play. On the main screen (depicted in Fig. 1a) two playing options are available: "Scratch 1 ticket" and "Scratch N tickets". Selecting the first option, the user can scratch a single ticket and discover the prize (if any) just by moving a finger across the smartphone display. Hence, the instant-lottery simulator looks like the real one in two fundamental aspects of the game: (1) the probability of getting each prize is the same in both situations and (2) the students have to scratch in

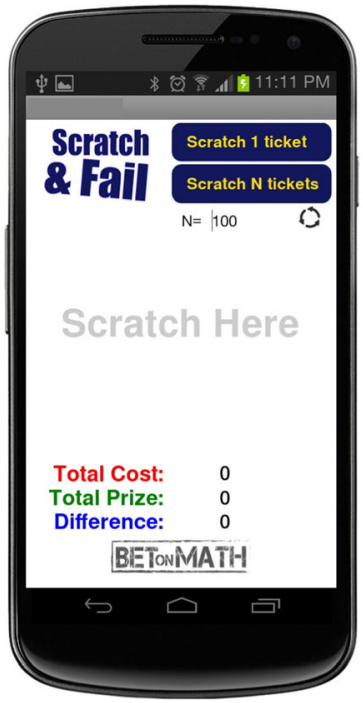

(a)

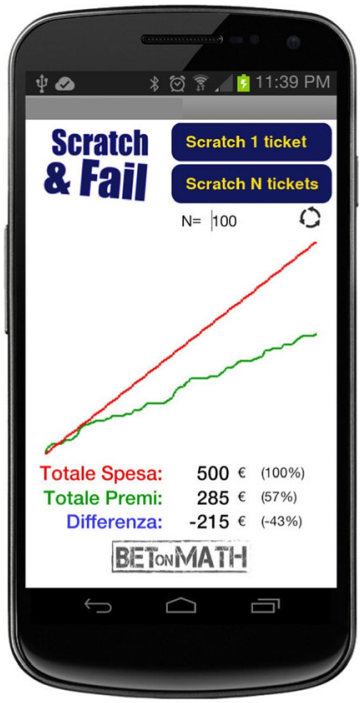

(b)

Fig. 1 The instant-lottery simulator. In (a), where it is written "Scratch here" in light grey, the students have to scratch with their finger and a prize (or no prize) can be found. In (b), a simulation of 100 scratched tickets has been performed 
order to find out any prize. This similarity allows us to recreate, in the classroom, a situation that is similar to the real one: emotions, tensions, actions and decisions that emerge in the simulated acts of scratching resemble very closely the ones carried out by actual gamblers, as experts of gambling addiction noticed while looking at videotaped student activity during the intensive analyses carried out together with us. However, distinguishing elements from the real game have been introduced in the app, in order to stimulate thinking and foster learning: (1) the messages for "no prize" and "you win 5 euros" have been modified to "you have already lost 5 euros" and "you win 5 euros, but you have already spent them in order to buy the ticket", respectively; (2) at the bottom of the page, there is a summary of money spent virtually for the tickets (red), the sum of the obtained prizes (green), and the difference between prizes and expenses (blue), which represents the net balance of the game. Once the ticket is scratched, the summary is updated.

In our research hypotheses, the "Scracth 1 ticket" task allows the students to experience the very low probability of winning a high-value prize. Hence, they experience the very high probability of losing their money. The "Scratch $\mathrm{N}$ tickets", indeed, allows the students to experience what happens when a large number of tickets is bought. Hence, they experience the near-certainty of losing more and more money as they play more and more times. It is possible to select the number of tickets and to visualise the results graphically. As the ticket counter progresses, a straight red line (whose slope represents the constant cost of each ticket) is drawn together with a less predictable green curve representing the total value of prizes that have been awarded (Fig. 1b).

We assume that students are graphically fluent, a priori. Our assumption is grounded in the natural pattern-recognition ability that people possess, as has been put forward by Gigerenzer (1991), and is exploited in the context of EDA (see Eichler and Vogel 2014). A posteriori, after extensive classroom observation, we can claim that our assumption was right. However, we intend to explore this issue in the future using a specifically dedicated research desing.

\section{Methodology}

The research question is: how can the app help the students to realise how gambling works, and can it stimulate the students to apply a mathematical lens to better understand gambling? In order to answer to this question, we tested the app out with several secondary school classes, and we videotaped the students' encounter with the app. We look at students' gestures, postures, glances, tone of voice, to infer about their thinking in learning. The result of our analysis is a reinterpretation of the theoretical approaches that constitute the background of our research in a new context. Specifically, we look at the students' gestures, touch, sight and emotions, and we explore the way the device activates them, as well as how they frame the interaction with the device at both the emotional and cognitive levels. We, thus, consider the possibility of depicting a landscape of potential relationships among gesture, perception and emotion, and to examine the ones (if any) in which learning can occur in the context of betting practices.

We present and analyse an excerpt that has been selected from a videotaped lesson that took place in a grade 12 class in May 2014. This is part of an extensive classroom observation carried out on May 2014, which allowed us to obtain more than 20 hours of 
videotaped lessons. Recently, another extensive period of classroom observation took place during January-February 2015: we obtained another 35 hours of video-recordings. The excerpt we report on here resembles some common dynamics that we have observed during both periods.

In the excerpt, two students, Claudio and Luigi, are working as a pair with Luigi's Android smartphone. At a certain point, a student from another group joins them, before leaving after a while. The third student's name is Giorgio. Part of the discussion that follows the presentation of the excerpt relates to the design of the app. To this end, we follow Antle and Wise's (2013) suggestion of providing details about the design of a tangible user interface (TUI) - as design choices might have a significant impact on learning - and not to leave unattended the critical and interdependent design of the learning activity, in which TUI will be used.

\section{Claudio and Luigi}

After having installed the app on his Android smartphone, Claudio has just opened the instant-lottery simulator and he is carrying out his first experiments. Luigi sits beside him, watching. The two-minute excerpt under analysis begins with Claudio clicking on "Scratch 1 ticket". With his finger, he virtually scratches the ticket, observes the outcome and clicks again on "Scratch 1 ticket". During the first 23 seconds, he scratches 7 tickets: only the first one has a prize, and we can observe exultation in Claudio's reaction:

\section{0:02 C: Yeah! I have won!}

Claudio is concentrated on the game, making the same sequence of gestures repeatedly: clicking, scratching, clicking, scratching, and so on. Claudio's posture tells that he is completely focused on the simulator: his back is curved, his arms are embracing the simulator, his head is fixed. The only part of his body that moves is his left hand (Fig. 2a).

We can see the student is passive in receiving the outcome of the instant lottery and his reactions are passive emotional reactions to the outcome. Apart from the first ticket (exultation), his emotional reactions reveal a tension, a desire to get a winning ticket. We can see this tension embodied in Claudio's posture: he is motionless, his tensed

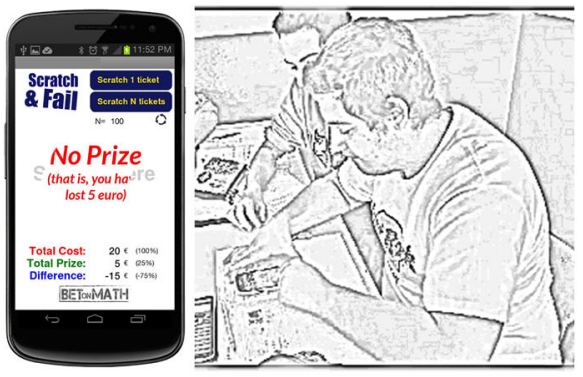

(a)
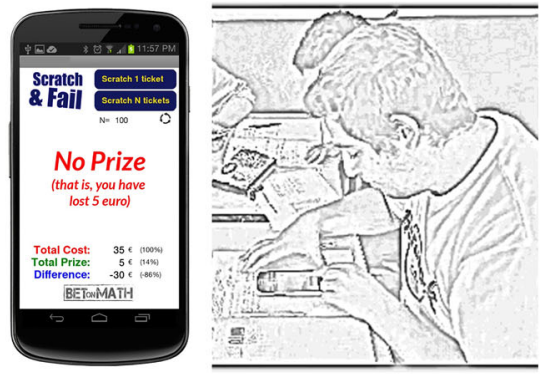

(b)

Fig. 2 Claudio's posture in his interaction with the instant-lottery simulator 
body statically expecting to get the next win. This expectation, this tension is the motive of Claudio's repeated actions of clicking and scratching. At 00:14 Claudio's classmate, Giorgio, asks:

00:14 G: Can you stop?

00:15 C: [shaking his head] No, I can't stop

This short interaction takes place during Claudio's repeated sequence of gestures. An external observer, as Giorgio is, is struck by Claudio's involvement in the instantlottery, and invites him to stop. But Claudio is impervious to Giorgio's invitation. At 00:23 Claudio notices something and he stops scratching for a while:

00:23 C: Ah! It says here how much I've lost.

There is a change in his emotional reaction: from exultation to disillusion. We perceive this in the tone of his voice, but also his posture changes: his back is less curved and his arms no longer embrace the simulator (Fig. 2b). Taking advantage of Claudio's stopping, Luigi takes over the role of clicking and scratching:

00:23 L: If I play, I win.

Luigi is very confident about his luck. From 00:23 to 00:32 Luigi clicks and scratches three times. He does not win and Claudio comments:

00:25 C: The next time, I will win. For sure (Fig. 3a)

00:27 L: No, the next time I will win!

At 00:25 and 00:27 we have underlined the words that correspond to an intensity increase in the tone of voice.

Luigi's act results as an invitation to Claudio to stop thinking about "how much he has lost" and to keep scratching. This is exactly what happens and Luigi's posture now reveals that he is engaged, too (Fig. 3b).

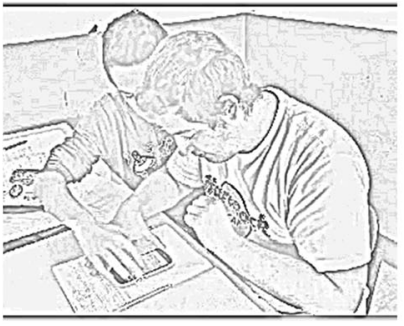

(a)

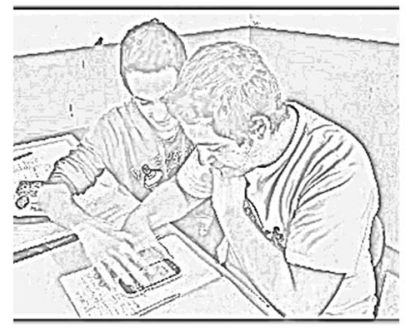

(b)

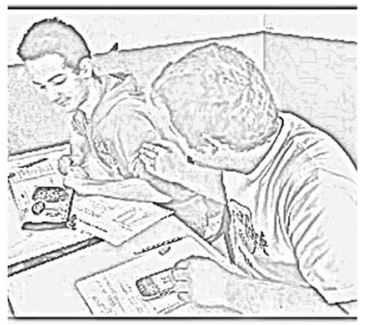

(c)

Fig. 3 Luigi is also engaged in the game 
At 00:35 Luigi glances away from Claudio and Claudio is again alone with the simulator. He touches Luigi's arm to involve him (Fig. 3c). Claudio gets a prize: 5 euros.

00:39 C: I have won!

00:40 L: This is how we can make Claudio happy

Luigi glances away again, but also the next ticket has a prize. Claudio looks at Luigi and says:

00:43 C: Another 5 euros!

In consequence, Luigi is again involved. At this point of the task, they decide to click on the button "scratch $\mathrm{N}$ tickets", and they fix $N=100$. The simulator takes 37 seconds (from 00:50 to 01:27) to scratch 100 tickets; the students are observing the outcomes and commenting on them:

00:53 C: Look! Look: I'm winning! (Fig. 4a)

00:55 C: We have found a prize of 1000 euros. Do you see? When it goes like this? (Fig. 4b)

01:08 L: [both students have remained silent for a while] What a bore! We're winning nothing.

01:12 C: Nooo, we have won squat...

01:15 L: Bbb, we won nothing.

01:16 C: [echoes with a gesture (Fig. 4c)]

01:18 L: We have lost, how much? 300, more than 300 euros.

01:21 C: Uh! (Fig. 4d) [looks at the teacher] We were above the red line. (Fig. 4e)

01:24 L: [starring at the simulator] We have won! (Fig. 4f)

At 00:55, Claudio observes a sharp increase; he mimics the steepness of the graph with his hand (Fig. 4b), and says: we've won 1000 euros. Claudio has exaggerated the prize, which was just 100 euros: we can notice that in 100 scratches one pays 500 euros; hence it is not possible to get a prize of 1000 euros and to have lost 300 euros at the end of the same simulation (contrary to what Luigi says at 01:18).

At 01:21 (Fig. 4d) and at 01:24 (Fig. 4f) the two students have found two different prizes: the first one makes the situation change from being "below the 
red line" (losing) to being "above the red line" (winning, namely the difference between the money paid out to play and combined value of the prizes earned is positive); the second one sets them definitively as winners. This is a rare event. It is much more common to end up with a losing situation, namely: the amount paid to play the game is more than the prizes earned. Thus, the students call the teacher over: this uncommon outcome is worth being noticed by her. This is really typical in gambling situations: only stories of winning are told.

In the sequel, the students make other simulations, clicking $N=100, N=300$, $N=1000$ tickets all at once. In all these repeated simulations, they lose their money. Then, they decide to click $N=50$ tickets (the reader can notice that the smaller the number of simulations, the greater the variance, hence with 50 tickets there is a higher probability of ending up a winner). At the very start,

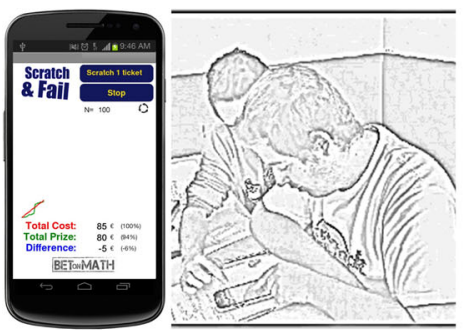

(a)

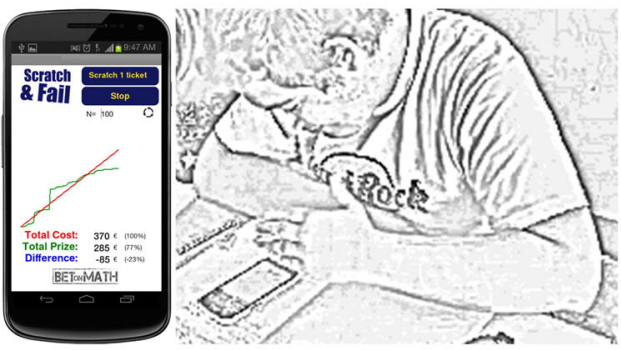

(c)

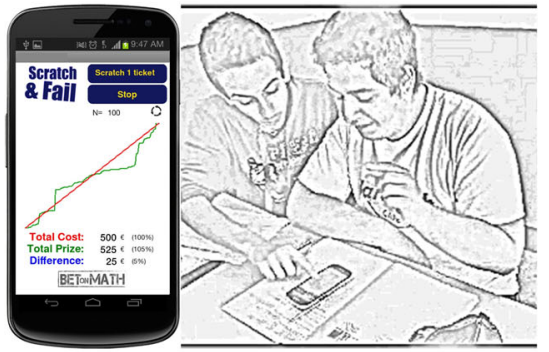

(e)
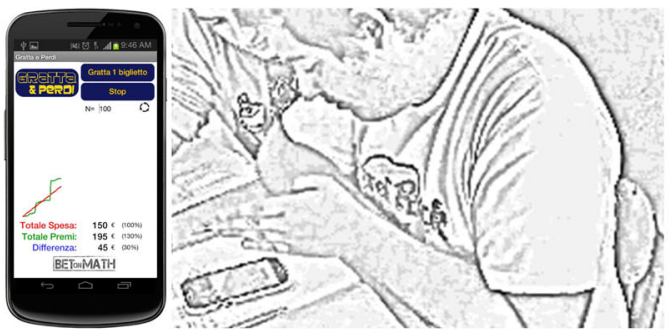

(b)

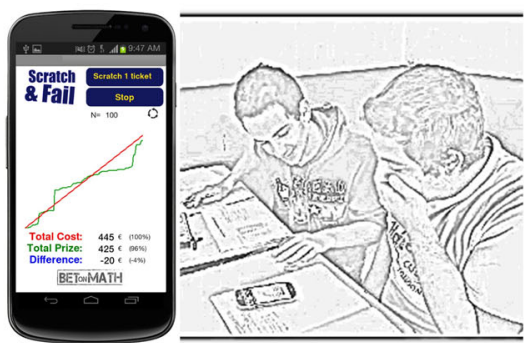

(d)

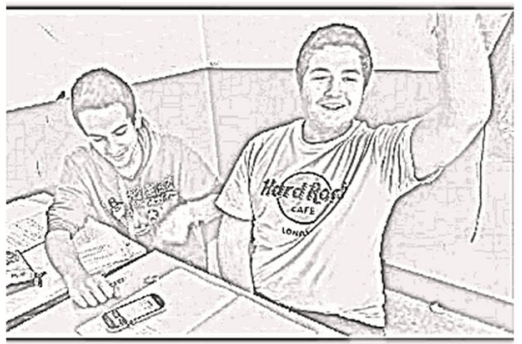

(f)

Fig. 4 Claudio and Luigi simulate 100 replications and they end up winning 
a winning ticket comes out, but then they keep not winning and Luigi comments:

05:41 L: Shit! We should have stopped at the 25th trial.

This is also noticed by Claudio:

05:47 C: Here we were at zero, right?

From that moment on, they lose money by buying tickets rather than earning money via prizes. But, one second later, something happens:

05:48 C: Yes! (Fig. 5a)

05:49 L: Prof... we have won AGAIN!

05:50 C: Prof, we have won!

05:51 L: We have won!

Called by her students, the teacher approaches, and both Claudio and Luigi are eager to tell her their story, a story of winners:

05:57 L: We have lost at 25...ehm, we have won 25 euros, but we have won. (Fig. 5b)

06:02 T: Oh my god! This smartphone is rigged!

Since the students tend only to notice and remember the times they win, the simulator has a "secret button", which opens another page that reveals the total amount of money that the students have paid, the amount they have earned (with prizes), and the (negative) difference between earned money and amount paid (Fig. $5 \mathrm{c}-\mathrm{d}$ ) ever since when the app has been installed on the smartphone. At this point of the activity, the teacher clicks on this button and the new page tells a completely different story: a (true) story of losers, not an (illusory) story of winners!

Looking at Fig. 5b, we can notice that Claudio is looking at the teacher confidently, and proud of his "luck". Luigi is exulting and telling her what has happened. Right after the teacher had clicked on the "secret button", in Fig. 5c Luigi stares intensely at the screen, trying to figure out what the numbers reveal, and in Fig. $5 \mathrm{~d}$ he is having an "AHA" experience: he understands that, in all, they have spent more money than they have won.

In the follow-up to this task, the teacher collects and reports on the blackboard the experiences lived by her students and mathematical modelling would arise. However, this falls outside the focus of this article. Hence, we now present a discussion about the use of such an instant-lottery simulator and its implications. 

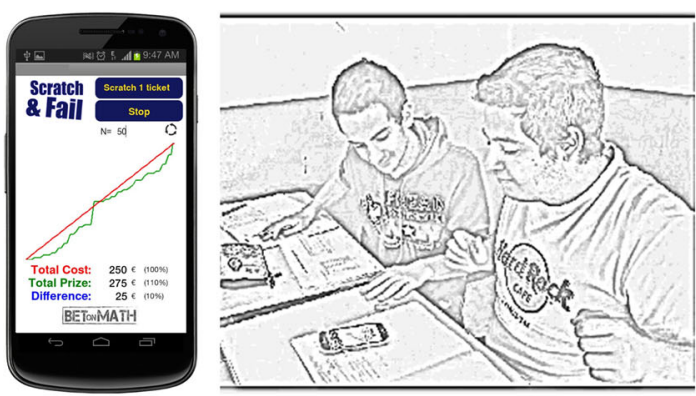

(a)
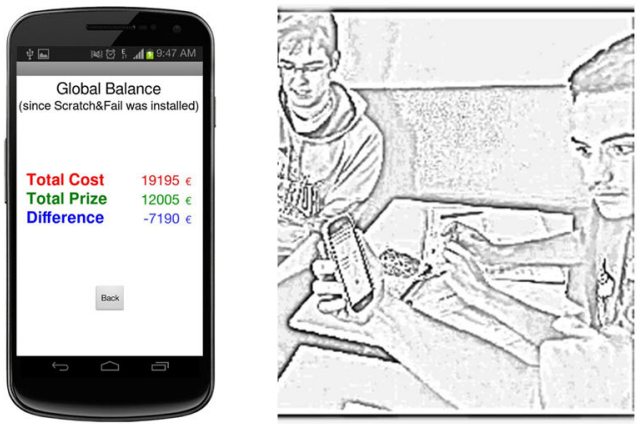

(c)

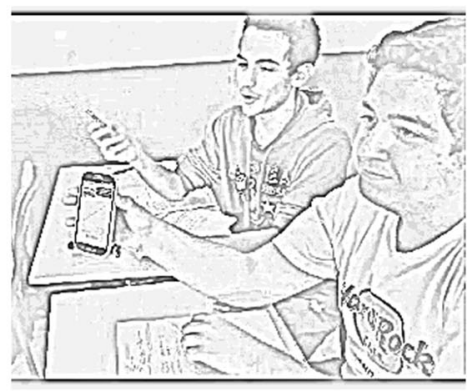

(b)

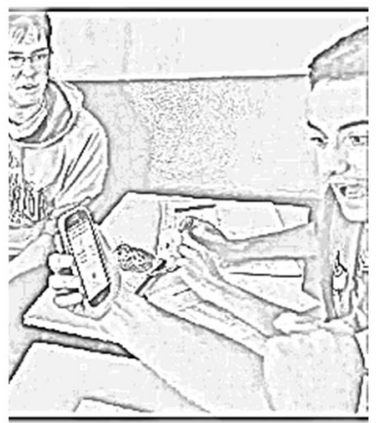

(d)

Fig. 5 From a story of winners to a story of losers

\section{Discussion of the Excerpt}

The discussion of the excerpt aims not only at digging deeper into some interesting elements of the episode, but also at speaking to the literature that informs our research and at discussing the role of the touchscreen app within the learning trajectory.

In our example, we can see that the feature of facilitating intuitive sense-making processes, in view of later mathematical formalisation (Eichler and Vogel 2014), is held by the simulator. At the beginning of the excerpt, for example, Claudio and Luigi experience the low probability of winning by scratching single tickets. This is mirrored by their repetitive utterances that focus on their loss, and the belief that they will win in the near future ("The next time, I will win"). With Antle and Wise (2013), we underline that this feature of the touchscreen app represents a singular opportunity to support learning interactions: the use of the app allows students to focus on empirical data and fosters the emergence of mathematical models as a need to understand patterns that seem significant. The students, in fact, firstly scratch $\mathrm{N}$ tickets and no theory is needed: they notice that the green line is below the red one more frequently (namely, that they lose money). This activity is also engaging: the students actually live the challenge of "winning". The possibility of virtually "scratching the screen" relates to a critical element (Antle and Wise 2013) of statistical learning: the empirical character of the problem situation indicates that data is needed (Garfield and Ben-Zvi 2008) before reliable hypothesising is possible. Only later in their activity, in fact, will the students 
try to figure out why they have lost money systematically. In this way, mathematical models will play a central role only after experiences have been had. This feature of the task setting is particularly relevant in the context of our research: if mathematical generalisation arises as a need to understand better an experience of loss, this could provide the engine for authentic learning to occur. Thus, the semiotic potential (Bartolini Bussi and Mariotti 2008) of the simulator has both a cognitive and an affective nature.

In the excerpt presented in this article, student activity with the simulator activates sensibilities to notice, to access mathematical generalisation. The instant-lottery simulator, in fact, activates touch and sight, as well as touch and sight activate the use of the device. At the beginning of the excerpt, for example, it is Claudio's touch that is activated by the device: the device says "Scratch here", clearly inviting him to touch it. Conversely, Claudio's touch activates the device. Also sight is activated by the device: Claudio can read the outcome and at a certain point his sight captures a detail that is important ("It says here how much I have lost" at 00:23), and this modifies Claudio's perception of the device (we see him detached for a while). Agreeing with Radford's (2013) construct of sensuous cognition, we see that touch and sight in relation to the simulator pave the way to emotional reactions and deep reflection about the phenomenon. This is achieved when the need to make sense of an experience of loss emerges, which comes out by means of a shock. At the end of the excerpt, in fact, the students are confident and proud of their luck ("We have won again!" at 05:49). But, when the teacher reveals the "secret page", Luigi realises that they have lost a lot of money: his facial expression in Fig. 5d is clearly the effect of a shock.

The diagram in Fig. 6 shows the main ideas that we have been discussing in this paper: the device activates (as well as it is activated by) touch and sight, but this is not enough to prompt sensuous cognition in full. Only if touch plays an active role and sight serves the purpose of just seeing what the finger should go does the student live a passive experience similar to that of real gamblers: he or she acts on the device, makes gestures that mimic the outcomes of the simulations, but only passive emotional reactions take place. And it is not enough that sight starts to play a central role and allows the student's sensibility to notice that a lot of money is being lost (as it happens at 00:23 for Claudio). An emotional and cognitive shock is necessary for the students to become active: active thinkers with emotions that sustain their learning and provide motives for learning to go on. It is only after the shock that sensuous cognition can emerge in its full potentiality: not only as the feature of living material bodies that have responsive sensations (Radford 2013), but as an unavoidable union of mind and body, emotion and knowledge, which allows the learner to understand deeply both the phenomenon of systematic loss and of himself (or herself) as a gambler.

Having clarified the two-way relationship within the elements of the diagram of Fig. 6, in what follows we dwell further on each element, to highlight and discuss specific issues. In this way, we discuss how and to what extent our theoretical background can be applied in the context of learning from a gambling context.

\section{Touch}

With respect to touch, we consider gesture and touch in terms of the material effects they achieve, and provide further evidence for Sinclair and de Freitas' 


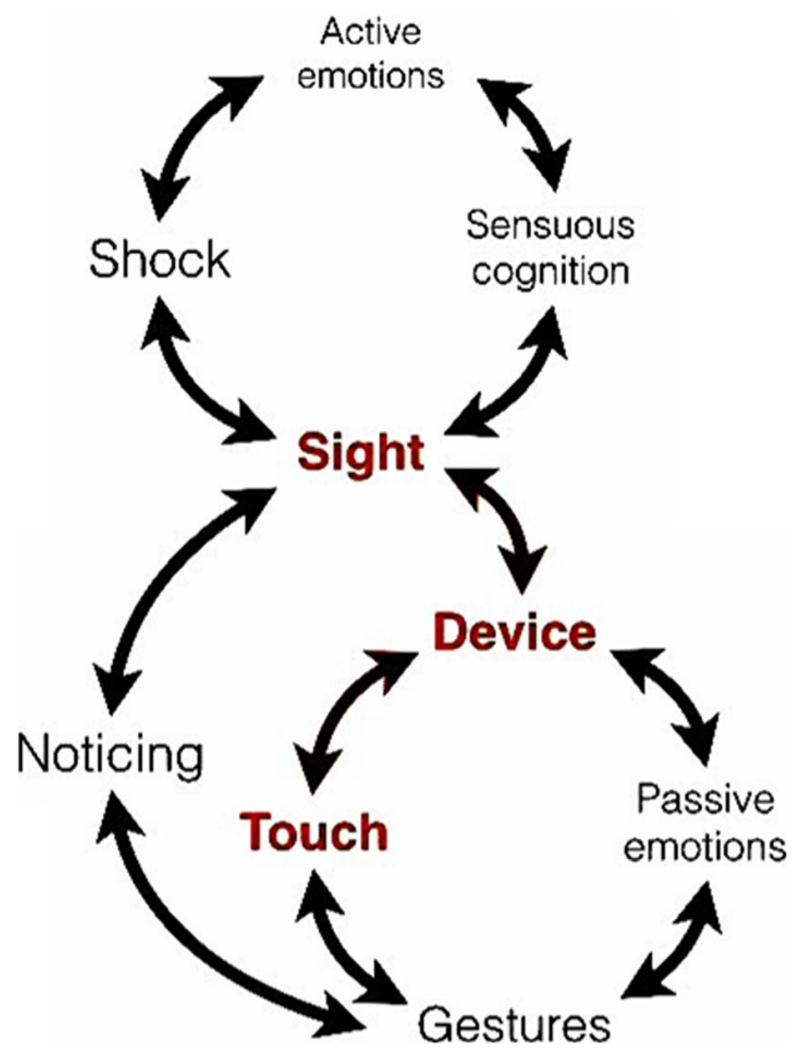

Fig. 6 Summarising the main ideas of our work

(2015) observation that there is an unavoidable relationship between gesture and touch. For example, consider the repeated act of clicking and scratching that Claudio carries out at the beginning. Immediacy is clearly one of the keywords that can describe the situation: there is no mediation among the act of clicking on "Scratch 1 ticket", the feeling of the finger when scratching the surface and his going back again to the button to be clicked.

We further argue that this absence of mediation is both physical and mental. Physical mediation is missing, since the finger actions are directly related to changes on the screen (rather than being indirectly related via mouse manipulation in previous screen-culture norms): the finger actions have a direct or relatively unmediated impact on the given surface. Mental mediation is also missing, since Claudio does not need to think about what he is doing. This is mirrored by his reaction to Giorgio's prompt to stop scratching: he claims he "cannot stop", no mediating reflection on the finger action is fostered, since only touch is involved.

This consideration ties back to the embodied mind paradigm: thinking is clearly embodied in this example. Claudio's tensed and sustained gaze at the screen and the muscular tension in his rather immobile manner of sitting are two expressions of the ongoing intense bodily phenomenon, and Claudio's cognition goes on with gestures and 
touch. In line with Antle and Wise (2013), we argue that the properties of the digital objects in the app resemble those of the physical objects in the real world, and the temporal properties of digital objects are maintained, but (differently from Antle and Wise) our app allows us to take into account tactile attributes also. Beyond the embodied mind paradigm, we also see a rather coercive feature of the touchscreen app: the learning trajectory needs to start with an intense and un-mediated series of acts of scratching.

\section{Gesture}

Looking at Fig. 2a, we notice that the only part of Claudio's body that moves is his left hand. To comment on this feature, we recall McNeil's (1992) understanding of gesture space. McNeil divides the space pertaining to the body of a person in terms of a centre and a periphery. The centre corresponds to the abdomen and shoulder, the periphery to the head, the arms, and the legs. In Claudio's case, only the left hand is moving and, according to McNeil, we could say that Claudio's gestures concern the periphery. Claudio's steady and fixed posture is central. The actual outcome of the simulator is very central, as we can see from Claudio's posture and his unrelenting gaze at it. The act of scratching with his finger is, indeed, peripheral: it just serves the purpose of allowing the outcome to unfold. Later in the activity, there are both (1) gestures that involve the whole body of Claudio and (2) gestures made only with the hand that are very central. Type 2 gestures require a deeper understanding of peripheral and central features, going beyond McNeil's taxonomy.

Regarding type 1 gestures, in Fig. $4 d$ there is an element of surprise: the green line is above the red one, and this observation involves Claudio's body as a whole. This is also mirrored by his utterance: "we were above the red line". It is not just where the green line is, the students themselves are above the red line. In Fig. 4f, exultance involves all of Claudio's body. This is also another example that thinking is necessarily embodied and emotional.

Regarding type 2 gestures, let us analyse Fig. $4 a-c$ and e. In Fig. 4a, Claudio is only pointing at the screen, but his words tell that what he is pointing at is all but peripheral: "Look: I am winning". First-person speech reveals that he is actually living this experience intensely. Figure 4b, c and d show mimicking gestures: in Fig. 4b and c Claudio mimics the steepness of the random green curve, while the gesture in Fig. 4d represents the distance between the red and the green curves. The first gesture, shown in Fig. 4b, helps him stress the importance of what he is saying in words: "We have found a prize of 1000 euros. Do you see? When it goes like this". Moreover, the tone of Claudio's voice, his emotional involvement and the use of such a sharp gesture lead us to conclude that this is central to Claudio's understanding of what is going on. Moreover, his exaggerating of the win (they have won far less than 1000 euros) speaks to his deep engagement. The second gesture, in Fig. 4c, substitutes for speech: Claudio is, in fact, replying to Luigi's utterance in this way. As in Fig. 4b, this gesture is central in his interaction with his classmate and with the artefact, so centrally that it replaces words. The third gesture, in Fig. 4e, seems to be redundant to speech, but we see it as a clue that the student as a whole (both his mind and body) is involved.

Type 1 and type 2 gestures suggest going beyond McNeill's classification to say that the centrality of a thought can be divorced from the part of the body that moves when such a thought is expressed in words. There is a similarity with emotions: psychologists and 
physiologists provide evidence that bodily disturbances (that we have when we react emotionally to a stimulus) could not be equated with sensed emotion. In experiments with dogs and cats, the removal of the body parts where bodily changes resides in situations of anger, fear and rage, did not affect the expected emotional states: namely, they felt the same (see Radford 2014). As well, a thought can be central to an individual even if a peripheral gesture emerges, or vice versa.

\section{Sight, Noticing and Shock}

At a certain point, sight comes to play a central role: it stops to serve only the purpose of seeing where fingers should go on the screen in order to get the desired outcome and activates noticing (Mason 2011). Sight, as Radford (2010) points out, is culturally and socially shaped: these students are both graph- and number-fluent, in the sense that they notice the distinctive features of the (random) graphs produced by the simulator, namely its steepness and the difference between the red and green lines, and they also grasp the meaning of the net balance.

The eye takes the role of shaping the students' noticing: noticing is both embodied and emotional. A first sudden and intense emotion is felt by Claudio when he notices that "It says here how much I've lost": this is rather a shock, in the sense that he lives for the first time an experience of loss, instead of focusing only on his wins. It is his sight, which catches the bottom of the page, that allows him to notice and activates his sensibility. This also has an effect on his practice, since for a while he stops scratching. Before this, emotions are frozen in tension to keep clicking and scratching. Sight activates noticing, noticing activates emotional response.

The major shock comes at the end of the excerpt, when the students are shown that in few minutes they have (virtually) spent almost 20,000 euros and (virtually) lost around 7000 euros. Again through sight, Luigi grasps the sense of the numbers on the page, and intense emotions accompany this moment of sudden revelation. This experience changes their attitude towards the simulator, and they stop using it. The illusion of winning has disappeared: we can claim that they are seeing the game with new eyes.

Going back to the design of the app, according to Antle and Wise (2013), we consider the possibility that potential actions, which are central to learning, will be enacted by the users. Potential actions, in our study, are not merely gestures on the app, but are predominantly cognitive/emotional reactions to the outcomes: noticing the net balance of the game, engagement, shock. Our extensive observations of secondary school students allow us to conclude that engagement is a relevant feature of the scratching activity, together with a tension related to the money that is virtually lost and earned. Students keep track of their virtual expenses, by checking the net balance on the screen, and usually comment on them. Not always is a shock present in student activity arising from other video-recorded tasks.

\section{Emotions: Active and Passive}

In the excerpt, Claudio lives different emotions: he is involved, enthusiastic, captured by the simulator, then he is detached for a while. Cognitive elements appear first as belief that he is going to win for sure, and this belief is strictly intertwined with emotions of involvement and pleasure. He enjoys his activity, both with his body and with his mind. Gestures mimic what is happening on the screen, exultation pervades his entire posture. He is self-confident 
when he calls the attention of his teacher, and he experiences intense frustration when confronting the "secret page". With Roth and Radford (2011), we see that emotions mediate the movement of the student activity itself: they accelerate the pace of compulsively clicking-and-scratching, as well as providing motivation to stop and reflect. However, we observe that the students are passive receivers of the outcomes of the simulator, and we refer to these reactions as emotional passive reactions. The presence of these passive reactions requires going beyond Roth and Radford's understanding of emotions, by incorporating the role of active and passive emotions.

Student activity with the instant-lottery simulator needs to create a passive situation, in order to resemble what actually happens in real games. This is different from having an emotional sense of the likelihood of failure: on the contrary, Claudio has an emotional sense of success; he truly believes that he will win, even if his emotions are passive. His emotions promote the action of the scratching, but at the same time they impede thinking. This situation is different from those taken into account by Roth and Radford, because the artefact that mediates the activity is different: the instantlottery simulator is designed to create passive emotional reactions instead of active thinking situations.

Is there a moment in which the students can become active? If we look at Fig. 2b, we see that Claudio has already noticed that, at the bottom of the page, it is said "how much I've lost". In this instant, he has an emotional reaction as well, but at the same time this allows a move away from the game, a motivation to stop and think, to become an active thinker.

Luigi's engagement is both active and passive: it is active, because Luigi takes the floor and scratches in first person (Fig. 3). But it is passive, at the same time, because the students have no choice: they cannot be detached. This is an interesting feature of gambling in general (Bastiani et al. 2011): it gives the player a feeling of active choices, but at the same time gamblers cannot choose to stop, since they are thoroughly engaged.

\section{Conclusions}

To summarise, the instant-lottery simulator can be seen as an example of a technological device that provokes emotional responses to gambling outcomes. Consequently, this study explores new possibilities for technological devices: that is, to foster emotional activation as an integral part of cognitive understanding and generalisation. To design an app bearing in mind its learning potential is a crucial feature both for learning and for the app design (Antle and Wise 2013).

Technology (as embodied in this Android app), touch, sight, emotion and cognition are indeed the keywords of this research. Not only this: they are also strictly interrelated with the experience of shock. Shock is emotionally as well as cognitively charged; it is triggered by perception and changes behaviour. The diagram in Fig. 6 represents an attempt to summarise the main ideas that have emerged in our work to date: the device activates perception, but if sight plays the sole role of seeing where the finger should go, then the students live passive emotional reactions that very well resemble the ones experienced by actual gamblers. Even when sight allows the students' sensibility to notice, it is difficult for the learners to leave the game. It is only through a shock that the students have a chance to become active thinkers. It is on this occasion that sensuous cognition exploits its full potential. 
Acknowledgments The project reported in this article was funded by Politecnico di Milano through the $5 \times$ 1000 Polisocial Award 2013 in collaboration with Fondazione Politecnico di Milano. We thank Mirko Maracci for his precious insight and for the inspiring conversations about the device. We also thank the psychologists of AND (Azzardo e Nuove Dipendenze - Gambling and New Addictions) - Daniela Capitanucci, Roberta Smaniotto and Angela Biganzoli - for their thoughtful feedback about the functioning of the simulator among gamblers.

\section{References}

Andrà, C., \& Santi, G. (2013). Intuitive thinking in a context of learning. In A. M. Lindmeier, \& A. Heinze (Ed.), Proceedings of the 37th Conference of the Psychology of Mathematics Education (Vol.2, pp. 2532). Kiel, GE: PME.

Antle, A., \& Wise, A. (2013). Getting down to details: using learning theory to inform tangible research and design for children. Interacting with Computers, 25(1), 1-20.

Bartolini Bussi, M., \& Mariotti, M. (2008). Semiotic mediation in the mathematics classroom: Artifacts and signs after a Vygotskian perspective. In L. English, M. Bartolini Bussi, G. Jones, R. Lesh, \& D. Tirosh (Eds.), Handbook of international research in mathematics education, second revised edition (pp. 746-805). Mahwah, NJ: Lawrence Erlbaum.

Bastiani, L., Gori, M., Colasante, E., Siciliano, V., Capitanucci, D., Jarre, P., \& Molinaro, S. (2011). Complex factors and behaviors in the gambling population of Italy. Journal of Gambling Studies, 27(4), 1-13.

Burrill, G., \& Biehler, R. (2011). Fundamental statistical ideas in the school curriculum and in training teachers. In C. Batanero et al. (Eds.), Teaching statistics in school mathematics - challenges for teaching and teacher education: A joint ICMI/IASE study (pp. 57-69). New York, NY: Springer.

Capitanucci, D. (2012). Strategie di prevenzione del gioco d'azzardo patologico tra gli adolescenti in Italia. L'utilizzo di strumenti evidence-based per distinguere tra promozione e prevenzione. [Strategies for preventing gambling abuse among teenagers in Italy. The use of evidence-based tools to distinguish between advertising and prevention.]. The Italian Journal on Addiction, 2(3-4), 139-146.

Contucci, P. (2012). Una questione di soldi. [A question of money] Social News., 03/2012. http://www. socialnews.it/articoli/una-questione-di-soldi/.

Eichler, A., \& Vogel, M. (2014). Three approaches for modelling situations with randomness. In E. Chernoff, \& B. Sriraman (Eds.), Probabilistic thinking (pp. 75-99). Dordrecht, NL: Springer.

Gal, I. (2002). Adults' statistical literacy: Meanings, components, responsibilities. International Statistical Review, 70(1), 1-51.

Garfield, J., \& Ben-Zvi, D. (2008). Developing students' statistical reasoning. New York, NY: Springer.

Gigerenzer, G. (1991). How to make cognitive illusions disappear: beyond "Heuristics and biases". European Review of Social Psychology, 2(1), 83-115.

Gigerenzer, G., \& Selten, R. (2001). Bounded rationality: The adaptive toolbox. Cambridge, UK: The MIT Press.

Kahneman, D., Slovic, P., \& Tversky, A. (1982). Judgement under uncertainty: Heuristics and biases. Cambridge, UK: Cambridge University Press.

Lane, D., \& Peres, S. (2006). Interactive simulations in the teaching of statistics: Promise and pitfalls. Proceedings of the Seventh Annual Meeting of the International Conference on the Teaching of Statistics, Salvador, BR. Retrieved on line on September 1, 2015. http://iase-web.org/documents/papers/ icots7/7D1_LANE.pdf.

Lane, D., \& Tang, Z. (2000). Effectiveness of a simulation on transfer of statistical concepts. Educational Computing Research, 22(4), 383-396.

Liljedahl, P. (2013). Illumination: Cognitive or affective? In M. S. Hannula, P. Portaankorva-Koivisto, A. Lane, \& L. Naveri (Eds.), Proceedings of the 18th international conference on mathematical views (MAVI) (pp. 187-200). Helsinki, FI: University of Helsinki.

Mason, J. (2011). Noticing: Roots and branches. In M. Sherin, V. Jacobs, \& R. Philipp (Eds.), Mathematics teacher noticing: Seeing through teachers' eyes (pp. 35-50). New York, NY: Routledge.

McNeill, D. (1992). Hand and mind: What gestures reveal about thought. Chicago, IL: University of Chicago Press.

Radford, L. (2008). The ethics of being and knowing: Towards a cultural theory of learning. In L. Radford, G. Schubring, \& F. Seeger (Eds.), Semiotics in mathematics education: Epistemology, history, classroom, and culture (pp. 215-234). Rotterdam, NL: Sense Publishers. 
Radford, L. (2010). The eye as a theoretician. For the Learning of Mathematics, 30(2), $2-7$.

Radford, L. (2013). Sensuous cognition. In D. Martinovic, V. Freiman, \& Z. Karadag (Eds.), Visual mathematics and cyberlearning (pp. 141-162). New York, NY: Springer.

Radfords, L. (2014). Of love, frustration, and mathematics: A cultural-historical approach to emotions in mathematics teaching and learning. In B. Pepin \& B. Rösken-Winter (Eds.), From beliefs and affect to dynamic systems: (Exploring) a mosaic of relationships and interactions (pp. 25-49). New York, NY: Springer.

Roth, W.-M., \& Radford, L. (2011). A cultural historical perspective on teaching and learning. Rotterdam, NL: Sense Publishers.

Siller, H. S., \& Maßß, J. (2012). Learning mathematics or losing money - betting as a topic for mathematics education. Teaching Mathematics Applications, 31(2), 65-83.

Sinclair, N., \& de Freitas, E. (2015). The haptic nature of gesture: rethinking gesture with new multitouch digital technologies. Gesture, in press.

Tukey, J. W. (1972). Data analysis, computation and mathematics. Quarterly for Applied Mathematics, 30, 51-65.

Vygotsky, L. S. (1999). The collected works of L. S. Vygotsky, vol. 6 (R.W. Rieber Ed.). New York, NY: Kluwer 